\title{
Monitoring dapsone self-administration in a multidrug therapy programme
}

\author{
ANNE-MARIE VAN ASBECK-RAAT* \\ \& MARIJKE BECX-BLEUMINK† \\ * Elective medical student, Erasmus University Rotterdam, Nether- \\ lands; †Director of ALERT Leprosy Control, Addis Ababa, \\ Ethiopia
}

Accepted for publication 5 September 1985

Summary In the ALERT Leprosy Control Programme implementation of multidrug therapy (MDT) started in January 1983. The majority of the patients had received dapsone monotherapy prior to MDT. To assess the intake of dapsone in the MDT programme the urine spot test is done in all the paucibacillary patients during the 4 th and 6 th supervised treatment day; with the multibacillary patients during the 4th, 6th, 12th, 18th and 24th supervised treatment. Results of the 4th and 6th treatment round are presented and discussed.

Of the 721 patients tested the overall percentage of patients with a positive test was $90.9 \%$. Patients with a previous duration of treatment of more than 3 years were found to be significantly less compliant than others. Determinants like age, sex, disability grade or having a leprosy contact in the family did not influence compliance in a significant way.

\section{Introduction}

In leprosy control programmes patients on dapsone monotherapy are regarded as regular attenders if they have collected $75 \%$ or more of the tablets they were expected to collect during a year. The collection of drugs for self-administration (attendance) is generally used as a measure for drug intake (compliance) by the patients. However compliance studies by way of urine testing for the presence of dapsone in several countries showed that only $40-70 \%$ of the patients had taken the drug before attending the clinic. ${ }^{1-14}$ One of the reasons for treatment failure with dapsone has been the irregularity of drug intake.

In the ALERT MDT programme the WHO recommended regimens have been introduced. ${ }^{15}$ These are:

Paucibacillary leprosy_rifampicin $600 \mathrm{mg}$ once a month, supervised, for 6 
months; and dapsone $100 \mathrm{mg}$ daily for 6 months, self-administered.

Multibacillary leprosy-rifampicin $600 \mathrm{mg}$ once a month, supervised; dapsone $100 \mathrm{mg}$ daily, self-administered; and clofazimine $300 \mathrm{mg}$ once monthly, supervised, and $50 \mathrm{mg}$ daily, self-administered.

For paucibacillary patients the attendance for supervised treatment is the most important factor to determine whether a patient should be regarded as cured. They can be released from chemotherapy after having collected 6 doses of supervised treatment and the 6 months of dapsone for daily self-administration within a period of 9 months. ${ }^{16}$ Multibacillary patients have to continue MDT for at least 2 years and until their skin smears are negative. ${ }^{15}$ They have to collect the 24 doses of supervised treatment and the daily dapsone and clofazimine for selfadministration within a period of 36 months. ${ }^{16}$

For the group of patients who received monotherapy prior to MDT, the regularity of attendance is the important criterium for release, as the majority of them will have had negative skin smears already at the start of MDT. Compliance in MDT is even more critical than in dapsone monotherapy because irregularity of drug intake may result in unmanageable situations, i.e. multiple resistance. The WHO Studygroup stresses that 'to maintain regular drug intake has now become a managerial task par excellence and needs priority attention'. ${ }^{15}$ The International Federation of Anti-Leprosy Associations (ILEP) asks, in its publication The introduction of multidrug therapy in lepros $y^{17}$ for special evaluation studies, among which is the testing of compliance to monitor the intake of the drugs prescribed.

\section{Objectives of this study}

The objectives of this study are: to get information on whether or not patients take the unsupervised component (dapsone) of MDT; and to obtain determinants of patients' compliance behaviour.

At ALERT the spot test has been introduced to detect dapsone in urine. It was described in 1965 by de Castro and recommended by WHO in 1966 but has, despite its simplicity, not been used widely in the field, apart from India. ${ }^{12,13,21-25}$ The test was found insensitive by some $\mathrm{e}^{20}$ but more recently a good correlation with the dapsone/creatinine method was reported. ${ }^{13,24,25}$

For clofazimine, the second unsupervised drug in multibacillary leprosy, no satisfactory test has been developed yet. However, we may probably assume that in most cases dapsone intake means clofazimine intake as well, especially because many leprosy patients have lost faith in dapsone and show a tendency to consume capsules. ${ }^{18}$ Therefore it is likely that clofazimine has been taken when the urine test is positive for dapsone. ${ }^{19}$ Furthermore our impression was that the vast majority of patients showed a distinct clofazimine discoloration of the skin, of 
which only a few have complained so far. In the MDT programme the spot test is done during the 4 th, 6 th, 12 th, 18 th and 24 th supervised treatment round. This publication gives the results of the 4th and 6th treatment round and is the first to report on compliance testing by way of the urine spot test in an MDT programme.

\section{Patients and methods}

All patients who started MDT in the 13 Addis Ababa town clinics during the period May-July 1984 and in the 11 clinics of Yerer \& Kereyu area during June and July 1984 were included. Surprise home visits were not done as they are not feasible in the field and moreover were not found to render significantly different results as compared to routine clinic visits. ${ }^{11}$

The urine of 721 patients was tested on the 4th and 6th supervised treatment round. Patients who did not attend during the scheduled clinic days were not included. However, most patients who did not attend during the scheduled day, came one or more days later. Also excluded were patients who were absent in the treatment round prior to the test (18), and patients who had a dapsone allergy (2) or could not pass urine (3). The spot test is done by pipetting a drop of fresh urine on filter paper impregnated with modified Ehrlich's reagent. When dapsone is present, an inner spot of orange to yellow colour appears; a yellow ring in the periphery is due to urea. A very faint orange spot was recorded as \pm but considered as positive. In the case of a negative test a drop of $1 \mathrm{~N} \mathrm{HCl}$ was added to the urine specimen and the test was repeated to exclude false negatives. Because of instability of the solution a positive control could not always be included. However, we did not experience any problem in reading the results. Recently a stable positive control solution was developed. ${ }^{19} \mathrm{We}$ may reasonably assume that our + and \pm group is identical with the positive category as indicated by the positive control solution mentioned.

A positive test means that on average dapsone was taken 4 days ago but probably no more during the last 3 days before testing. A negative test indicates that dapsone was not taken according to schedule and possibly so long ago that the blood level has fallen below the MIC. ${ }^{19}$

Information was collected from each patient about sex, age, classification, leprosy contact in the family, disability grade and duration of previous treatment.

Table 1. Attendance rates and urine test results in 13 Addis Ababa town clinics.

\begin{tabular}{|c|c|c|c|c|c|c|c|c|c|c|}
\hline $\begin{array}{l}\text { Treatment } \\
\text { round }\end{array}$ & $\begin{array}{l}\text { Patients } \\
\text { expected }\end{array}$ & $\begin{array}{l}\text { Patients } \\
\text { attended }\end{array}$ & $\%$ & $\begin{array}{l}\text { Urine } \\
\text { tested }\end{array}$ & $\begin{array}{l}\text { Urine } \\
\text { pos. }\end{array}$ & $\%$ & $\begin{array}{c}\text { Urine } \\
\pm\end{array}$ & $\%$ & $\begin{array}{l}\text { Urine } \\
\text { neg. }\end{array}$ & $\%$ \\
\hline 4 th & 568 & 500 & $88 \cdot 0$ & 494 & 415 & $84 \cdot 0$ & 44 & 8.9 & 35 & $7 \cdot 1$ \\
\hline 6 th & 582 & 481 & $82 \cdot 6$ & 473 & 396 & $83 \cdot 7$ & 22 & $4 \cdot 7$ & 55 & $11 \cdot 6$ \\
\hline
\end{tabular}




\section{Results and discussion}

Tables 1 and 2 show the test results. On average, $85.0 \%$ of the patients who were expected during the supervised treatment day attended. The percentage of attenders with a positive test ranged from 88.4 to 93 . When nonattenders are included in the denominator the minimal range of positive tests still varies

Table 2. Attendance rates and urine test results in 11 clinics in Yerer \& Kereyu area.

\begin{tabular}{|c|c|c|c|c|c|c|c|c|c|c|}
\hline $\begin{array}{l}\text { Treatment } \\
\text { round }\end{array}$ & $\begin{array}{l}\text { Patients } \\
\text { expected }\end{array}$ & $\begin{array}{l}\text { Patients } \\
\text { attended }\end{array}$ & $\%$ & $\begin{array}{l}\text { Urine } \\
\text { tested }\end{array}$ & $\begin{array}{l}\text { Urine } \\
\text { pos. }\end{array}$ & $\%$ & $\begin{array}{c}\text { Urine } \\
\pm\end{array}$ & $\%$ & $\begin{array}{l}\text { Urine } \\
\text { neg. }\end{array}$ & $\%$ \\
\hline 4 th & 148 & 121 & $81 \cdot 8$ & 114 & 98 & $86 \cdot 0$ & 8 & $7 \cdot 0$ & 8 & $7 \cdot 0$ \\
\hline 6th & 165 & 142 & 86 & 142 & 126 & $88 \cdot 7$ & 3 & $2 \cdot 1$ & 13 & $9 \cdot 2$ \\
\hline
\end{tabular}

Table 3. Data of patients with a positive and negative urine test

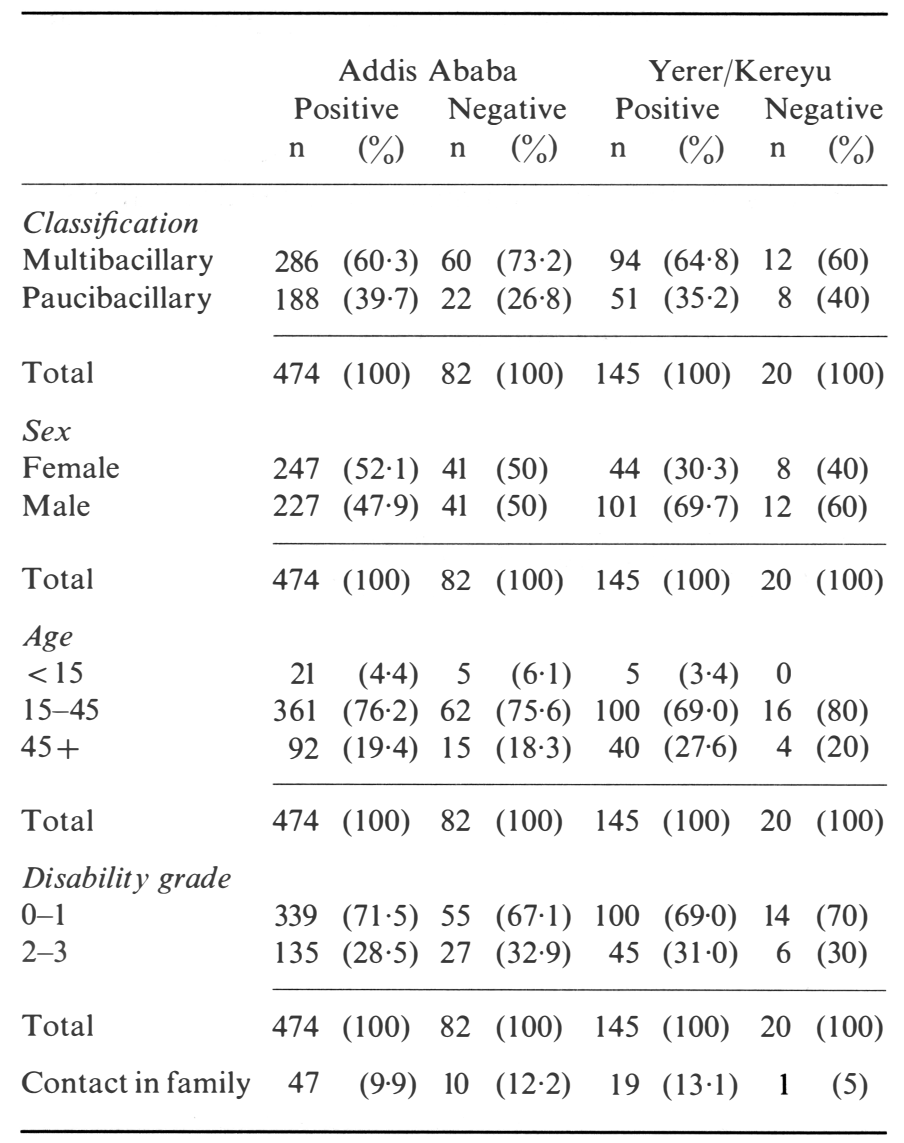


Table 4. Duration of treatment in relation to compliance (Addis Ababa and Yerer \& Kereyu combined).

\begin{tabular}{lrrrr}
\hline $\begin{array}{l}\text { Duration of } \\
\text { treatment }\end{array}$ & \multicolumn{2}{c}{$\begin{array}{c}\text { Positive } \\
\text { test }\end{array}$} & \multicolumn{2}{c}{$\begin{array}{c}\text { Negative } \\
\text { test }\end{array}$} \\
\hline $\begin{array}{l}\text { less than 1 year } \\
1-3 \mathrm{yr}\end{array}$ & 46 & $(7 \cdot 5)$ & 3 & $(2 \cdot 9)$ \\
$3-5 \mathrm{yr}$ & 188 & $(30 \cdot 6)$ & 16 & $(15 \cdot 7)$ \\
$5+\mathrm{yr}$ & 115 & $(18 \cdot 7)$ & 29 & $(28 \cdot 4)$ \\
& 265 & $(43 \cdot 2)$ & 54 & $(52 \cdot 9)$ \\
\cline { 2 - 6 } Total & 614 & $(100)$ & 102 & $(100)$ \\
\hline
\end{tabular}

between 72 and $81 \%$. Tables 3 and 4 contain general data on compliant patients, as well as data for the patients who were negative once (92) or twice (10). A statistically significant relationship was found between noncompliance and duration of treatment prior to MDT longer than 3 years $\left(p<0.01\right.$ in $\chi^{2}$ test). Paucibacillary patients were more compliant than multibacillary patients $(p=0 \cdot 10)$. A significantly reduced compliance in patients under the age of 15 or above 45 was not observed, nor did we find a correlation between compliance and sex, disabilities or having a leprosy contact in the family.

A number of studies have dealt with the relationship between patients' variables and compliance. ${ }^{3,9,11-13,24,26}$ The picture emerging from it is not uniform, but most authors have agreed on the following conclusions, of which the first was confirmed also in this study:

1 Patients with a long duration of treatment are less compliant. Associated with this is the observation that patients on the lepromatous side of the spectrum (who tend to have been treated longer) are less compliant than those on the tuberculoid side.

2 Patients younger than 15 years and older than about 45 are less compliant.

Some authors found a negative relationship between compliance and having a leprosy contact, having disabilities and being a female, while others could not confirm this.

\section{Conclusions and recommendations}

The intake of dapsone in the ALERT MDT programme as measured by way of the urine spot test appears to be very encouraging, especially when compared to 
the $60 \%$ compliance in the monotherapy era. ${ }^{10}$ Among others it indicates the enthusiasm of both patients and staff for the new programme.

The relationship between noncompliance and a long history of treatment has been confirmed in this study. Sex, age, disability grade and a contact in the family were not found to be important determinants. It is recommended that feedback of the test results is given to the patients afterwards. In the ALERT programme this was done by the supervisors in the health education talk and this was very satisfactory. Individual feedback was occasionally given, mostly to the patients who had been negative twice.

The urine spot test will be incorporated in the routine work of the field staff during the next treatment rounds. This is highly recommended also for other control programmes. The spot test is sufficiently sensitive, it is cheap $(\$ 0 \cdot 2 / 100$ tests), but above all it is simple enough to perform on the spot in the field.

\section{Acknowledgments}

We would like to thank the staff of the ALERT Leprosy Control Department and the laboratory for their kind cooperation; Hubert van Dijk, Dutch medical student, for initiating the testing; Hans A Valkenburg, Professor of Epidemiology in Rotterdam and Han Huikeshoven, Royal Tropical Institute, Amsterdam for their valuable comments. Financial aid was received from the QM GastmannWichers stichting.

\section{References}

${ }^{1}$ Low SJM, Pearson JMH. Do leprosy patients take dapsone regularly? Lepr Rev, 1974; 45: 218 23.

2 Ellard GA, Gammon PT, Harris JM. The application of urine tests to monitor the regularity of dapsone self-administration. Lepr Rev, 1974; 45: 224-34.

3 Jesudasan K, George B, Chacko CJG, Taylor PM, Kurian PV, Job CK. An evaluation of the self-administration of DDS in Gudiyatham Taluk. Lepr India, 1976; 48: 668-76.

${ }^{4}$ Huikeshoven HCJ, Honhoff C, Van Eys GJJM, Anten JGF, Mayer JMA, Van Helden HPT. Weekly self-medication of leprosy patients monitored by DDS/creatinine ratios in urine. Lepr Rev, 1976; 4; 201-9.

${ }^{5}$ Balakrishnan S. Monitoring self-administration of dapsone by patients. Lepr India, 1977; 49: 364-71.

${ }^{6}$ Gyi KM, Lwin MM, Myaing YY, Oo KM, Shwe T. Reliability of dapsone self-administration in the Rangoon area. Lepr Rev, 1978; 49: 283-6.

7 Naik SS. Irregularity of dapsone intake in infectious leprosy patients attending an urban treatment centre. Its magnitude and causes. Lepr India, 1978; 50: 45-53.

${ }^{8}$ Nigam P, Siddique MIA, Pandey NR, Awasthi KN, Sriwastava RN. Irregularity of treatment in leprosy patients. Its magnitude and causes. Lepr India, 1979; 51: 521-32.

9 Hagan KJ, Smith SE, Gyi KM, Lwin MM, Myaing YY, Oo KM, Shwe T, Tin KM, Than KN, Hla T, Kywe WW. The reliability of self-administration of dapsone by leprosy patients in Burma. Lepr Rev 1979; 50: 201-11. 
10 Ellard GA, Pearson JMH, Hale GS. The self-administration of dapsone by leprosy patients in Ethiopia. Lepr Rev, 1981; 52: 237-243.

11 Cates CJ. An assessment of dapsone self-administration in Gudiyatham Taluk. How should urinary dapsone/creatinine ratios be used? Lepr Rev, 1981; 52: 55-64.

12 Kumar A, Balakrishnan S. Monitoring the regularity of self-administration of dapsone by leprosy patients. Lepr India, 1982; 54: 664-70.

${ }^{13}$ Kumar A. Treatment compliance by leprosy out-patients and its monitoring under field condition. Ind J Lepr, 1984; 56: 313-18.

${ }_{14}$ Huikeshoven HCJ. Editorial. Int J Lepr, 1981; 49: 228-58.

${ }_{15}$ Chemotherapy of leprosy for control programmes; WHO Technical Report nr. 675; 1982.

${ }_{16}$ Manual for implementation of multidrug therapy in ALERT; first revised version; 1984.

17 The introduction of multidrug therapy for leprosy; ILEP 1983.

18 Naik SS, Revankar CR, Ganapati R, quoted in 19 as personal communication.

${ }_{19}$ Huikeshoven HCJ. A simple urine spot test to monitor dapsone self-administration. Its potential value in leprosy control programmes. Dissertation, London School of Hygiene and Tropical Medicine, 1984.

${ }^{20}$ Ellard GA, Gammon PT, Helmy HS, Rees RJW. Urine tests to monitor the self-administration of dapsone by leprosy patients. Am J Trop Med Hyg, 1974; 23: 464-70.

${ }^{21}$ Balakrishnan S. Application of a spot test for detection of DDS in urine. Lepr India, 1968; 40: 15.

22 Balakrishnan S. A note on the screening for DDS in urine by spot test. Lepr India, 1969; 41: 77-8.

${ }^{23}$ Noordeen SK, Balakrishnan S. Spot test for DDS in urine under field conditions. Ind J Med Res, 1972; 60: 367-71.

${ }^{24}$ Kumar A, Balakrishnan S. Operational study to monitor the regularity of dapsone intake by leprosy out-patients. Le pr India, 1983; 55: 521-7.

${ }^{25}$ Irudaya Raj PP, Lourdumary S, Aschoff M, Balakrishnan S. A comparison of screening tests for dapsone in urine. Lepr India, 1983; 55: 528-38.

${ }^{26}$ Hertroijs AR. A study of some factors affecting the attendance of patients in a leprosy control scheme. Int J Lepr, 1974; 42: 419-27. 